\title{
Low-power laser irradiation inhibits arecoline-induced fibrosis: an in vitro study
}

\author{
Mei-Chun Yeh ${ }^{1, \star}$, Ker-Kong Chen ${ }^{1,2, \star}$, Min-Hsuan Chiang ${ }^{1,3}$, Chia-Hsin Chen ${ }^{3,4,5}$, Ping-Ho Chen ${ }^{1}$, \\ Huey-Er Lee ${ }^{1,2}$ and Yan-Hsiung Wang ${ }^{1,3}$
}

Oral submucous fibrosis (OSF) is a potentially malignant disorder that is characterized by a progressive fibrosis in the oral submucosa. Arecoline, an alkaloid compound of the areca nut, is reported to be a major aetiological factor in the development of OSF. Low-power laser irradiation (LPLI) has been reported to be beneficial in fibrosis prevention in different damaged organs. The aim of this study was to investigate the potential therapeutic effects of LPLI on arecoline-induced fibrosis. Arecolinestimulated human gingival fibroblasts (HGFs) were treated with or without LPLI. The expression levels of the fibrotic marker genes alpha-smooth muscle actin ( $\alpha$-SMA) and connective tissue growth factor (CTGF/CCN2) were analysed by quantitative realtime reverse transcription polymerase chain reaction (RT-PCR) and western blots. In addition, the transcriptional activity of CCN2 was further determined by a reporter assay. The results indicated that arecoline increased the messenger RNA and protein expression of CCN2 and $\alpha$-SMA in HGF. Interestingly, both LPLI and forskolin, an adenylyl cyclase activator, reduced the expression of arecoline-mediated fibrotic marker genes and inhibited the transcriptional activity of CCN2. Moreover, pretreatment with SQ22536, an adenylyl cyclase inhibitor, blocked LPLI's inhibition of the expression of arecoline-mediated fibrotic marker genes. Our data suggest that LPLI may inhibit the expression of arecoline-mediated fibrotic marker genes via the cAMP signalling pathway. International Journal of Oral Science (2017) 9, 38-42; doi:10.1038/ijos.2016.49; published online 24 February 2017

Keywords: adenylate cyclase; alpha-smooth muscle actin; connective tissue growth factor; fibrosis; low-power laser irradiation

\section{INTRODUCTION}

Oral submucous fibrosis (OSF) is a chronic, progressive, wellrecognized potentially malignant disorder of the oral cavity and has a malignant transformation potential of $7 \%-13 \% .^{1}$ OSF is mainly found in people in Southern Asia and is strongly associated with the use of areca nut and the duration and frequency of chewing habits. ${ }^{1-2}$

The exact mechanism that causes OSF is very complicated and is still not completely understood. Areca nut chewing causes fibrosis owing to reduced collagenase activity and increased collagen formation. Moreover, arecoline, a major alkaloid compound of the areca nut, was found to stimulate collagen synthesis when it is exposed to buccal mucosal fibroblasts and gingival fibroblasts. ${ }^{3-5}$

The pathway by which arecoline induces collagen accumulation has been reported by many authors. ${ }^{5-6}$ Although the precise mechanisms remain unclear, two protein factors, transforming growth factor (TGF) $\beta$ and connective tissue growth factor (CTGF/CCN2), are widely regarded as the main mediators of fibrogenesis. ${ }^{7-8}$
TGF- $\beta$ is a proinflammatory cytokine that regulates multiple cellular responses, including proliferation, differentiation, and apoptosis. ${ }^{9}$ During fibrogenesis, TGF- $\beta$ is the primary cytokine responsible for increased collagen production and decreased collagen degradation in OSF. In addition, TGF- $\beta$ is considered to be involved in myofibroblast differentiation of $\alpha$-SMA-containing stress fibres. ${ }^{10}$

CCN2 is a multifunctional heparin-binding glycoprotein that is expressed at low levels normally but expressed at higher levels in fibrotic tissues. ${ }^{11}$ Many studies have demonstrated that CCN2 regulates multiple processes that contribute to fibrogenesis, including fibroblast proliferation, migration, adhesion, and ECM production. ${ }^{12}$ The overexpression of CCN2 has been found to be associated with the onset and progression of different types of fibrosis in a number of human tissues, including abnormal cutaneous fibrosis (scleroderma) ${ }^{13}$ and pulmonary, ${ }^{14}$ hepatic, ${ }^{15}$ renal, ${ }^{16}$ and gingival fibrosis. ${ }^{17}$

Low-power laser irradiation (LPLI) has been used for the treatment of musculoskeletal pain, wound healing, and chronic or acute

${ }^{1}$ School of Dentistry, College of Dental Medicine, Kaohsiung Medical University, Kaohsiung, Taiwan; ${ }^{2}$ Department of Dentistry, Kaohsiung Medical University Hospital, Kaohsiung Medical University, Kaohsiung, Taiwan; ${ }^{3}$ Orthopaedic Research Center, College of Medicine, Kaohsiung Medical University, Kaohsiung, Taiwan; ${ }^{4}$ Department of Physical Medicine and Rehabilitation, Kaohsiung Municipal Ta-Tung Hospital, Kaohsiung Medical University, Kaohsiung, Taiwan and ${ }^{5}$ Department of Physical Medicine and Rehabilitation, Kaohsiung Medical University Hospital, Kaohsiung Medical University, Kaohsiung, Taiwan

*These authors contributed equally to this work.

Correspondence: Dr HE Lee, School of Dentistry, College of Dental Medicine, Kaohsiung Medical University, 100 Shih-Chuan 1st Road, Kaohsiung 80708, Taiwan E-mail: huerle@kmu.edu.tw

Dr YH Wang, School of Dentistry, College of Dental Medicine, Kaohsiung Medical University, 100 Shih-Chuan 1st Road, Kaohsiung, Kaohsiung 80708, Taiwan

E-mail: yhwang@kmu.edu.tw

Accepted 8 October 2016 
inflammation in the last few decades. ${ }^{18-20}$ A few studies have also demonstrated that LPLI can reduce tissue fibrosis in the kidneys, muscle, and Achilles tendon. ${ }^{21-23}$ Therefore, we investigated the molecular mechanisms of LPLI on the expression of arecolinemediated fibrotic marker genes in human gingival fibroblasts (HGFs).

\section{MATERIALS AND METHODS}

\section{Reagents}

Anti- $\alpha$-SMA (catalogue no. 14968 ) and anti- $\alpha$-tubulin (catalogue no. 3873) antibodies were purchased from Cell Signaling Technology (Beverly, MA, USA). The anti-CCN2 (catalogue no. PHG0286) antibody was purchased from Thermo Fisher Scientific (Waltham, MA, USA). All other reagents were obtained from Sigma-Aldrich (St Louis, MO, USA) unless otherwise noted.

\section{Ethics statement}

The research protocol was approved by the Institutional Review Board of the Kaohsiung Medical University Hospital (IRB number: KMUHIRB-20110031). All the participants provided their written informed consent to participate in this study and gave consent for the publication of the clinical details. All clinical investigation was conducted according to the principles expressed in the Declaration of Helsinki.

\section{Cell culture}

After obtaining informed consent from all the patients and approval from the hospital, healthy marginal gingival tissue was collected during the surgical extraction of impacted third molars. HGFs were isolated according to a modified protocol proposed by Hillmann et al. ${ }^{24}$ In brief, the tissue was washed with $1 \times$ phosphate-buffered saline (PBS) and minced into pieces. Then, the tissue was digested in a solution of $0.2 \%$ type I collagenase and $0.1 \%$ EDTA at $37^{\circ} \mathrm{C}$ for $6 \mathrm{~h}$. The cells were centrifuged at $1000 \mathrm{rpm}$ for $5 \mathrm{~min}$, and the pellet was resuspended in culture medium, which was keratinocyte serum-free medium (catalogue no. 17005042; Gibco-BRL, Rockville, MD, USA) mixed with low-glucose Dulbecco's modified Eagle's medium (catalogue no. 31600034; Gibco-BRL, Rockville, MD, USA) at a 1:1 ratio. The medium was supplemented with $12.5 \mathrm{mg}$ bovine pituitary extract, $1.25 \mu \mathrm{g} \mathrm{rEGF}$ protein, $0.03 \mu \mathrm{g} \cdot \mathrm{mL}^{-1}$ insulin, $0.1 \mathrm{mmol} \cdot \mathrm{mL}^{-1}$ $\mathrm{N}$-acetyl-cysteine, $0.1 \mathrm{mmol} \cdot \mathrm{mL}^{-1}$ L-ascorbic acid 2-phosphate magnesium, 5\% FBS, and $1 \%$ penicillin/streptomycin. The HGFs were cultured at $37^{\circ} \mathrm{C}$ in a humidified chamber with $5 \% \mathrm{CO}_{2}$. Once confluent, the HGFs were trypsinized and replated into $10 \mathrm{~cm}$ culture dishes. The HGFs in this experiment were used within seven passages.

\section{Low-power laser irradiation}

A $660 \mathrm{~nm}$ gallium-aluminium-arsenide (GaAlAs) laser was purchased from Transverse Industries (Taipei, Taiwan). The maximum power of the laser was $70 \mathrm{~mW}$, and the distance between the laser source and the bottom of the plate could be adjusted to match the intended target size. The power density was $15.17 \mathrm{~mW} \cdot \mathrm{cm}^{-2}$, and $8 \mathrm{~J} \cdot \mathrm{cm}^{-2}$ of irradiation energy was applied to the cells once a day. After arecoline treatment, the LPLI-treated group received laser irradiation at the same time as arecoline treatment. All the irradiation experiments were performed on a clean experimental bench at room temperature. The control groups were processed under the same conditions except without laser irradiation.

\section{MTT assay}

The HGFs were cultured to $60 \%-70 \%$ confluence in 96-well plates. After treatment with arecoline $(0,10,100,200,500$,
$1000 \mu \mathrm{mol} \cdot \mathrm{L}^{-1}$ ) for $48 \mathrm{~h}$, the 3-[4,5-dimethylthiazol-2-yl]-2,5-diphenyltetrazolium (MTT) reagent was added to each well. After $4 \mathrm{~h}$ of incubation at $37^{\circ} \mathrm{C}$, the formazan reaction products in each well were dissolved in dimethyl sulfoxide solution, and the absorbance at $570 \mathrm{~nm}$ was measured using an enzyme-linked immunosorbent assay (ELISA) reader.

\section{Quantitative real-time reverse transcription polymerase chain reaction}

The total messenger RNA (mRNA) was extracted from the cells using TRIzol reagent as recommended by the manufacturers. Subsequently, $2 \mu \mathrm{g}$ RNA was reverse transcribed to first-strand complementary DNA (cDNA). Quantitative real-time reverse transcription polymerase chain reaction (qRT-PCR) was performed in a $12.5 \mu \mathrm{l}$ reaction mixture with CDNA, forward and reverse primers for each gene, and SYBR green (catalogue no.1708882; Bio-Rad, Hercules, CA, USA) in a CFX Connect Real-Time Detection System. The qRT-PCR primers used for the following human genes were as follows: GAPDH $\left(5^{\prime}-\mathrm{CA}\right.$ ATGACCCCTTCATTGACC-3' forward and 5'-TTGATTTTGGAG GGATCTCG-3' reverse), CCN2 (5'-GGAAAAGATTCCCACCCAAT $-3^{\prime}$ forward and 5'-TGCTCCTAAAGCCACACCTT-3' reverse), and $\alpha$-SMA (5'-CCGACCGAATGCAGAAGGA- $3^{\prime}$ forward and 5'-ACA GAGTATTTGCGCTCCGGA-3' reverse). The measurements were performed in triplicate. The mRNA expression levels were estimated from the threshold cycle $(\mathrm{Ct})$ value, and GAPDH expression was used as an internal control for data analysis.

\section{Western blots}

After the cells were washed twice with $1 \times$ PBS, the proteins were extracted from the cells using a RIPA lysis buffer. The cell lysate, with $40 \mu \mathrm{g}$ of protein, was analysed on $12 \%$ sodium dodecyl sulfatepolyacrylamide gel electrophoresis (SDS-PAGE) gels and transferred to polyvinylidene fluoride membranes. The membranes were blocked with $5 \%$ nonfat milk, followed by an overnight incubation with antibodies against $\alpha$-SMA (dilution 1:1 000) and CCN2 (dilution 1:2000) and were probed with $\alpha$-tubulin (dilution 1:1000)for a loading control. All the membranes were detected using the chemiluminescence detection system.

\section{Dual luciferase assay}

The reporter plasmid pTS589, which contains a human CCN2 promoter $(-802$ to $+22 \mathrm{bp})$, was kindly provided by Dr Kubota $\mathrm{S}$ of Okayama University. ${ }^{25}$ The cells were cotransfected with the pTS589 vector $(1 \mu \mathrm{g})$ and pTK-Renilla vector (20 ng; catalogue no. E224; Promega, Madison, WI, USA) using Lipofectamine 2000 (catalogue no. 11668019; Invitrogen, Carlsbad, CA, USA), and the transfection procedure was performed according to the manufacturer's instructions. After $24 \mathrm{~h}$, luciferase activity was measured using a Dual Luciferase Reporter Assay System (catalogue no. E1910; Promega, Madison, WI, USA) and was analysed by a Top Count Microplate Scintillation and Luminescence Counter (Packard Biosciences, Waltham, MA, USA).

\section{Statistical analysis}

SPSS version 17.0 (SPSS, Chicago, IL, USA) was used for statistical analysis. The results are expressed as the mean \pm standard deviation. Statistically significant differences were determined using analysis of variance followed by a post hoc Tukey's test for multiple comparisons. A $P$-value less than 0.05 was considered statistically significant. 


\section{RESULTS}

Arecoline affects cell viability of HGFs

We used an MTT assay to examine the effect of arecoline on HGFs at different concentrations $\left(0,10,100,200,500,1000 \mu \mathrm{mol} \cdot \mathrm{L}^{-1}\right)$. The results indicated that the absorbance values of MTT decreased significantly when the HGFs were treated with arecoline at concentrations higher than $200 \mu \mathrm{mol} \cdot \mathrm{L}^{-1}$ (Figure 1).

\section{Arecoline increases fibrotic marker gene expression, but LPLI} inhibits fibrotic marker gene expression in HGFs

First, we verified the fibrogenic effect of arecoline on HGFs. After treatment with or without arecoline, the protein expression levels of fibrotic marker genes, CCN2 and $\alpha$-SMA, were examined by western blotting. The results indicated that both $\mathrm{CCN} 2$ and $\alpha$-SMA levels were slightly increased at day 3 , and the expression levels of CCN2 and $\alpha$ SMA were drastically increased at day 5 (Figure 2a). Next, we determined the effect of LPLI on arecoline-induced fibrotic gene expression.

The cells were treated with or without arecoline, followed by LPLI $\left(8 \mathrm{~J} \cdot \mathrm{cm}^{-2}\right)$ irradiation. Both CCN2 and $\alpha$-SMA protein levels were reduced in the LPLI-treated groups at day 3 and day 5 (Figure $2 \mathrm{~b}$ ). The data indicate that LPLI may reverse arecoline-induced fibrosis.

LPLI reduces fibrotic gene expression via the cAMP signalling pathway

Our previous studies indicated that the biostimulatory effect of LPLI may occur through the cAMP signalling pathway. Forskolin, an adenylyl cyclase activator, was used to pretreat the HGFs before arecoline was added. After 3 days and 5 days, we examined the protein expression of the fibrotic marker genes. LPLI alone and forskolin alone did not affect the protein expression levels of CCN2 and $\alpha$-SMA (Supplementary Figure S1). The results demonstrated that arecoline increased the protein expression levels of CCN2 and $\alpha$-SMA, but forskolin inhibited arecoline-stimulated fibrotic gene expression in the HGFs at day 5 (Figure 2c).

We further studied the mechanism of the LPLI-mediated antiarecoline effect in HGFs. Similar to the protein expression pattern, the mRNA expression levels of the CCN2 and $\alpha$-SMA genes were approximately 5 -fold higher than those of the control group after arecoline treatment for 5 days (Figures $3 \mathrm{a}$ and $3 \mathrm{~b}$ ). In addition, the

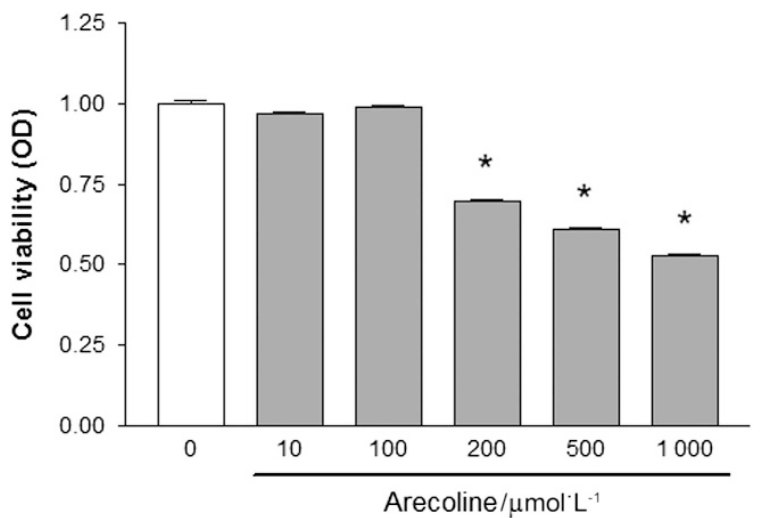

Figure 1 Arecoline reduces the cell viability of HGFs. The cells were treated with different concentrations of arecoline $(0,10,100,200,500$, and $\left.1000 \mu \mathrm{mol} \cdot \mathrm{L}^{-1}\right)$. The cell viability was monitored by MTT assay, and the optical densities (OD) at $570 \mathrm{~nm}$ were measured $(n=6)$. The data are shown as the mean \pm standard deviation. ${ }^{*} P<0.05$ relative to the control treatment group $\left(0 \mu \mathrm{mol} \cdot \mathrm{L}^{-1}\right)$. HGF, human gingival fibroblast. a

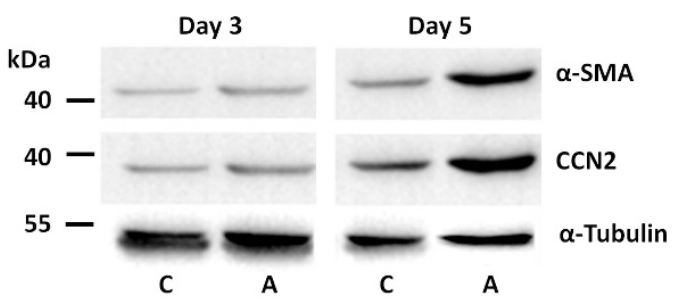

b Day 3

Day 5

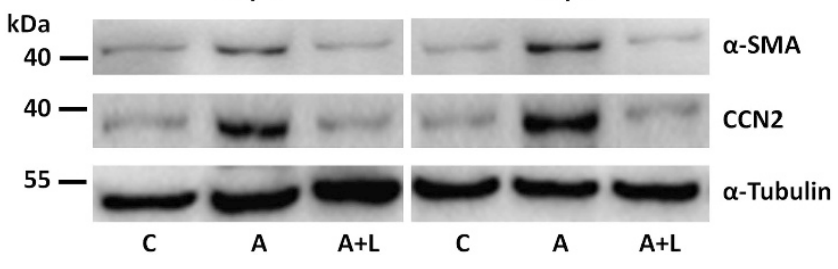

C Day 3

Day 5

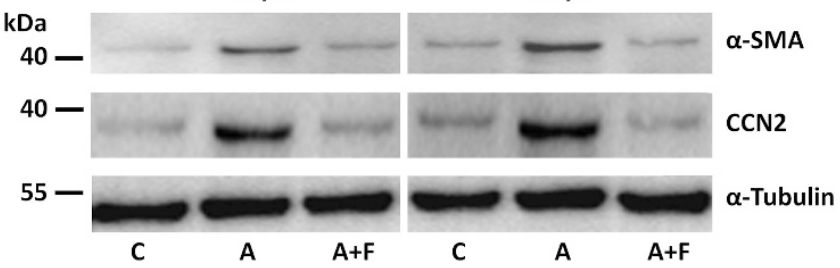

Figure 2 LPLI and forskolin inhibit arecoline-induced fibrotic marker gene expression in HGFs. (a) The fibrotic marker gene expression of arecolinetreated HGFs. (b) The effect of LPLI on arecoline-treated HGFs. (c) The effect of forskolin on arecoline-treated HGFs. The expression levels of fibrotic markers CCN2 and $\alpha$-SMA were detected at the indicated time points by western blot. Molecular weight markers are shown on the left. The $\alpha$-tubulin is used as a loading control. $\mathrm{C}$ indicates control group; $\mathrm{A}$ indicates the arecoline $\left(200 \mu \mathrm{mol} \cdot \mathrm{L}^{-1}\right)$ treatment group; $A+L$ indicates the group co-treated with arecoline $\left(200 \mu \mathrm{mol} \cdot \mathrm{L}^{-1}\right)$ and $\mathrm{LPLI}$; and A+F indicates the group co-treated with arecoline $\left(200 \mu \mathrm{mol} \cdot \mathrm{L}^{-1}\right)$ and forskolin $\left(60 \mu \mathrm{mol} \cdot \mathrm{L}^{-1}\right)$. HGF, human gingival fibroblast; LPLI, low-power laser irradiation; SMA, smooth muscle actin.

arecoline-induced mRNA expression of CCN2 was completely inhibited by forskolin and $\sim 65 \%$ inhibited by LPLI at day 5 (Figure $3 a$ ). Furthermore, SQ22536, an adenylyl cyclase inhibitor (cAMPi), was used to pretreat the arecoline-treated HGFs. The results indicated that cAMPi almost fully reversed the inhibitory effect of forskolin on CCN2 mRNA expression. Conversely, cAMPi significantly but partially ameliorated the inhibitory effect of LPLI on CCN2 mRNA expression (Figure 3a).

The arecoline-induced mRNA expression of $\alpha$-SMA was completely inhibited by forskolin and LPLI at day 5 (Figure 3b), and cAMPi significantly but partially reversed the inhibitory effect of forskolin and LPLI on $\alpha$-SMA mRNA expression. These data indicate that the cAMP signalling pathway could suppress fibrotic gene expression. Thus, cAMP activation may have a role in the anti-arecoline effect of LPLI.

LPLI elevates cAMP levels and inhibits arecoline-induced CCN2 promoter activation

To further confirm the interaction between arecoline and LPLI, we used a dual luciferase assay to monitor CCN2 promoter activity in HGFs. Similar to the effects of arecoline treatment on the CCN2 expression pattern of protein and mRNA, arecoline treatment 


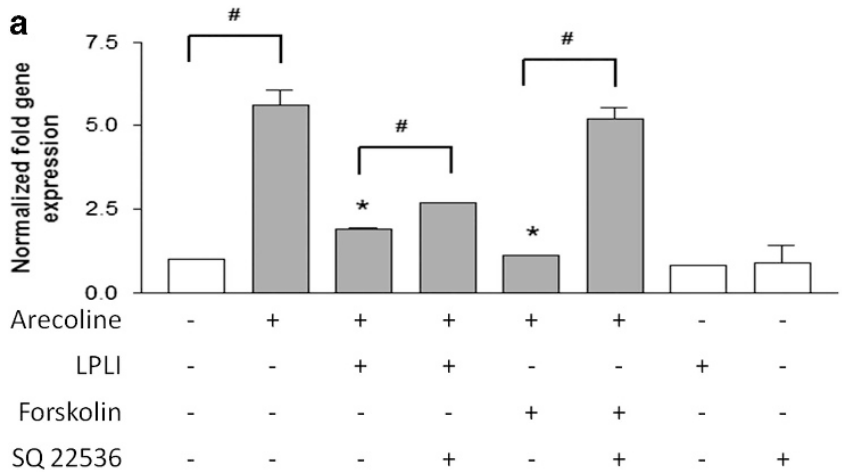

b

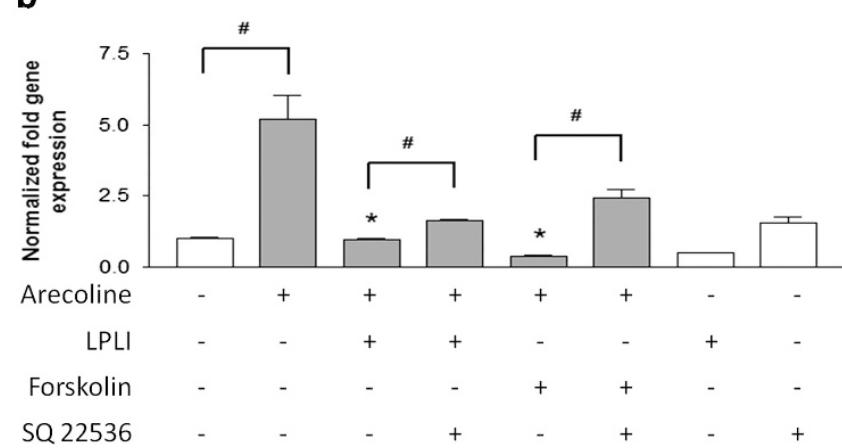

Figure 3 LPLI reduces fibrotic gene expression via the CAMP signalling pathway. HGFs were cultured in the absence or presence of arecoline $\left(200 \mu \mathrm{mol} \cdot \mathrm{L}^{-1}\right)$, forskolin $\left(60 \mu \mathrm{mol} \cdot \mathrm{L}^{-1}\right)$, and SQ22536(100 $\left.\mu \mathrm{mol} \cdot \mathrm{L}^{-1}\right)$, and the cells were treated with or without $\mathrm{LPLI}(8 \mathrm{~J} \cdot \mathrm{cm}-2)$. The $\mathrm{mRNA}$ expression levels of the fibrotic marker genes, CCN2, and $\alpha$-SMA were examined by qRT-PCR at day 5. (a) $\alpha$-SMA mRNA expression. (b) CCN2 mRNA expression. The data are shown as the mean \pm standard deviation. The statistical levels are indicated as follows: ${ }^{*} P<0.05$ compared with the arecoline group, and ${ }^{\#} P<0.05$ compared with the indicated group. HGF, human gingival fibroblast; LPLI, low-power laser irradiation; mRNA, messenger RNA; qRTPCR, quantitative reverse transcription PCR; SMA, smooth muscle actin.

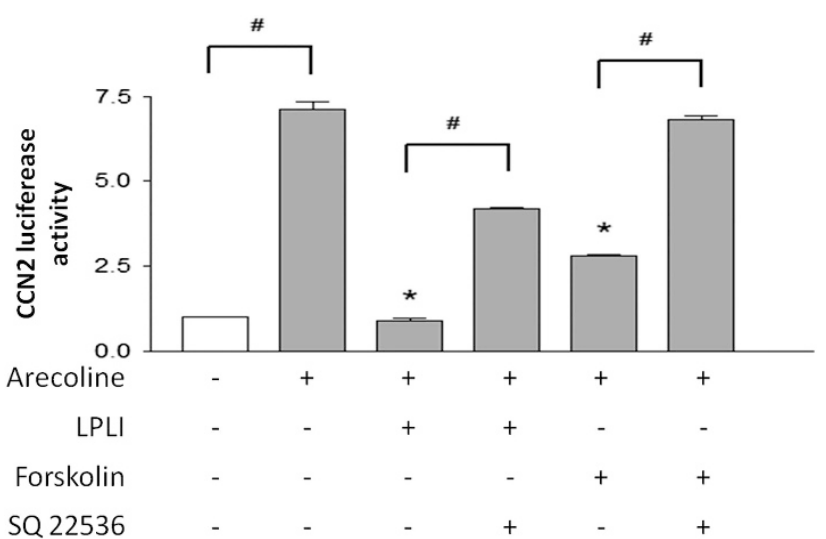

Figure 4 LPLI inhibits arecoline-induced CCN2 promoter activation by dual luciferase assay. HGFs were cotransfected with the pTS589 vector and pTKRenilla vector. Then, the cells were cultured in the absence or presence of arecoline $\left(200 \mu \mathrm{mol} \cdot \mathrm{L}^{-1}\right)$, forskolin $\left(60 \mu \mathrm{mol} \cdot \mathrm{L}^{-1}\right)$, and SQ22536 $\left(100 \mu \mathrm{mol} \cdot \mathrm{L}^{-1}\right)$, and the cells were treated with or without LPLI $\left(8 \mathrm{~J} \cdot \mathrm{cm}^{-2}\right)$. The cells were collected, and luciferase activity was measured as described under "Materials and Methods" section. The results are expressed as the mean \pm standard deviation from three independent experiments. The statistical levels are indicated as follows: ${ }^{*} P<0.05$ compared with the arecoline group, and $\# P<0.05$ compared with the indicated group. HGF, human gingival fibroblast; LPLI, low-power laser irradiation.

increased the CCN2 promoter activity by $\sim 7$-fold compared with that in the control group (Figure 4). Arecoline-induced CCN2 promoter activation was completely inhibited by LPLI and $~ 75 \%$ inhibited by forskolin (Figure 4). Moreover, cAMPi almost fully reversed the inhibitory effect of forskolin on CCN2 promoter activity. Conversely, cAMPi significantly but partially ameliorated the inhibitory effect of LPLI on CCN2 promoter activity (Figure 4).

\section{DISCUSSION}

OSF is a chronic oral mucosal disease that is characterized by epithelial atrophy and the progressive accumulation of collagen fibres in the lamina propria and the submucosal layer. This abnormal fibrosis always leads to stiffness of the mucosa, resulting in poor life quality for OSF patients. Although various treatments have been suggested for OSF over the past decades, no truly effective therapy is available to inhibit the progression of fibrosis.
The results of this study demonstrate for the first time, to the best of our knowledge, that LPLI suppresses changes in arecoline-associated fibrotic marker gene expression and inhibits the transcriptional activity of CCN2 in HGFs, and this effect may function via the cAMP signalling pathway. These data suggest that LPLI could possibly be a useful therapy for controlling OSF in the future.

A few other studies have also shown that LPLI can reduce fibrosis. In 2005, Fillipin et al. found that low-level laser therapy (Ga-As laser) can reduce fibrosis in an animal experimental model of Achilles tendon injury due to the beneficial effects of the treatment on the oxidant/antioxidant balance. ${ }^{21}$ In 2012, Oliveira et al. ${ }^{22}$ found that low-level laser therapy decreases renal interstitial fibrosis in an animal model of unilateral ureteral obstruction (UUO) by preventing tubular activation and transdifferentiation, which are the two processes that mainly drive renal fibrosis in the UUO model. In 2014, Alves et al. ${ }^{23}$ found that low-level laser therapy exerted a positive effect on the inflammatory process, MMP2 activity, and collagen organization and distribution in the process of rat skeletal muscle repair. To the best of our knowledge, this is the first report demonstrating that LPLI could inhibit the expression of arecoline-mediated fibrotic marker genes.

Our study also indicated that cAMP activation could inhibit the expression of arecoline-mediated fibrotic marker genes. This result is consistent with those of previous studies. Black et al. ${ }^{26}$ showed that prostaglandin E2 blocked TGF- $\beta$-induced CCN2 expression by cAMP cross-talk with the MAPK pathway in gingival fibroblasts. ${ }^{26}$ Schiller et $a .^{27}$ found that increased cAMP levels can modulate TGF- $\beta$ mediated expression of several ECM components in dermal fibroblasts. ${ }^{27}$ The results suggested that the cAMP pathway is a potent regulator of TGF- $\beta$-mediated effects, which are involved in ECM homeostasis. Other studies also reported that cAMP activation by specific chemicals blunts the transformation of fibroblasts to myofibroblasts and ECM formation in cardiac fibroblasts ${ }^{28-29}$ and lung fibroblasts. ${ }^{29}$ Furthermore, our previous studies suggested that the biostimulatory effects of LPLI may function through upregulating the cellular cAMP levels in human adipose-derived stem cells and human periodontal ligament cells. ${ }^{18,30}$

Our data demonstrated that the decrease in CCN2 and $\alpha$-SMA gene expression in arecoline-treated HGFs after forskolin and LPLI treatment was reversed by SQ22536 (adenylyl cyclase inhibitor). The results strongly indicate that upregulating the cellular cAMP level blocks arecoline-induced fibrotic marker gene expression, and the 
effect of LPLI may occur through activation of the cAMP signalling pathway. However, the reversal effect of SQ22536 in the LPLI-treated group was less than that in the forskolin-treated group. The effects of LPLI were not totally blocked by cAMP inhibitor treatment. These data might indicate that the effects of LPLI do not rely solely on the cAMP pathway and that other pathways may be involved in the effects of LPLI. Owing to the multiple complicated mechanisms of the biological effects of LPLI, further studies on other pathways should be performed to comprehensively elucidate the antifibrotic mechanisms of LPLI. A more detailed understanding of the molecular mechanism of the antifibrotic activity of LPLI is necessary for its application in future clinical practices.

In conclusion, our results demonstrate that the expression of fibrotic marker genes (CCN2 and $\alpha$-SMA) in HGFs increases under arecoline stimulation. LPLI and forskolin application can reduce the expression of these two fibrotic marker genes and inhibit the transcriptional activity of CCN2. Moreover, pretreatment of SQ22536 can block the inhibitory effects of LPLI on arecolinemediated fibrotic marker gene expression, indicating that LPLI may inhibit arecoline-mediated effects via the cAMP signalling pathway and can potentially be applied as an antifibrotic therapy in the future.

\section{ACKNOWLEDGEMENTS}

This study was supported by the Kaohsiung Municipal Ta-Tung Hospital (grant kmtth-102-010), and the Kaohsiung Medical University in Taiwan under the grant "Aim for the Top Universities Grant" (KMU-TP103B08).

1 Prabhu RV, Prabhu V, Chatra $L$ et al. Areca nut and its role in oral submucous fibrosis. J Clin Exp Dent 2014; 6(5): e569-e575.

2 Chole RH, Gondivkar SM, Gadbail AR et al. Review of drug treatment of oral submucous fibrosis. Oral Oncol 2012; 48(5): 393-398.

3 Yoithapprabhunath TR, Maheswaran T, Dineshshankar J et al. Pathogenesis and therapeutic intervention of oral submucous fibrosis. J Pharm Bioallied Sci 2013; 5(Suppl 1): S85-S88.

4 Arakeri G, Brennan PA. Oral submucous fibrosis: an overview of the aetiology, pathogenesis, classification, and principles of management. Br J Oral Maxillofac Surg 2013; 51(7): 587-593.

5 Khan S, Chatra L, Prashanth SK et al. Pathogenesis of oral submucous fibrosis. J Cancer Res Ther 2012; 8(2): 199-203.

6 Thangjam GS, Agarwal P, Balapure AK et al. Regulation of extracellular matrix genes by arecoline in primary gingival fibroblasts requires epithelial factors. J Periodontal Res 2009; 44(6): 736-743.

7 Rajalalitha P, Vali S. Molecular pathogenesis of oral submucous fibrosis-a collagen metabolic disorder. J Oral Pathol Med 2005; 34(6): 321-328.

8 Rockey DC, Bell PD, Hill JA. Fibrosis-a common pathway to organ injury and failure. N Engl J Med 2015; 372(12): 1138-1149.

9 Finnson KW, Arany PR, Philip A. Transforming growth factor beta signaling in cutaneous wound healing: lessons learned from animal studies. Adv Wound Care (New Rochelle) 2013; 2(5): 225-237.

10 Insel PA, Murray F, Yokoyama $U$ et al. cAMP and Epac in the regulation of tissue fibrosis. Br J Pharmacol 2012; 166(2): 447-456.

$11 \mathrm{Xu}$ SW, Leask A, Abraham D. Regulation and function of connective tissue growth factor/CCN2 in tissue repair, scarring and fibrosis. Cytokine Growth Factor Rev 2008; 19(2): 133-144.
12 Huang G, Brigstock DR. Regulation of hepatic stellate cells by connective tissue growth factor. Front Biosci (Landmark Ed) 2012; 17: 2495-2507.

13 Leask A, Sa S, Holmes A et al. The control of ccn2 (ctgf) gene expression in normal and scleroderma fibroblasts. Mol Pathol 2001; 54(3): 180-183.

14 Allen JT, Knight RA, Bloor CA et al. Enhanced insulin-like growth factor binding proteinrelated protein 2 (Connective tissue growth factor) expression in patients with idiopathic pulmonary fibrosis and pulmonary sarcoidosis. Am J Respir Cell Mol Biol 1999; 21(6): 693-700.

15 Paradis V, Dargere D, Vidaud M et al. Expression of connective tissue growth factor in experimental rat and human liver fibrosis. Hepatology 1999; 30(4): 968-976.

16 Ito Y, Aten J, Bende RJ, Oemar BS et al. Expression of connective tissue growth factor in human renal fibrosis. Kidney Int 1998; 53(4): 853-861.

17 Kantarci A, Black SA, Xydas CE et al. Epithelial and connective tissue cell CTGF/CCN2 expression in gingival fibrosis. J Pathol 2006; 210(1): 59-66.

$18 \mathrm{Wu}$ JY, Chen $\mathrm{CH}$, Wang $\mathrm{CZ}$ et al. Low-power laser irradiation suppresses inflammatory response of human adipose-derived stem cells by modulating intracellular cyclic AMP level and NF-KB activity. PLoS One 2013; 8(1): e54067.

19 Gal P, Mokry M, Vidinsky B et al. Effect of equal daily doses achieved by different power densities of low-level laser therapy at $635 \mathrm{~nm}$ on open skin wound healing in normal and corticosteroid-treated rats. Lasers Med Sci 2009; 24(4): 539-547.

20 Sakurai Y, Yamaguchi M, Abiko Y. Inhibitory effect of low-level laser irradiation on LPSstimulated prostaglandin E2 production and cyclooxygenase-2 in human gingival fibroblasts. Eur J Oral Sci 2000; 108(1): 29-34.

21 Fillipin LI, Mauriz JL, Vedovelli K et al. Low-level laser therapy (LLLT) prevents oxidative stress and reduces fibrosis in rat traumatized Achilles tendon. Lasers Surg Med 2005; 37(4): 293-300.

22 Oliveira FA, Moraes AC, Paiva AP et al. Low-level laser therapy decreases renal interstitial fibrosis. Photomed Laser Surg 2012; 30(12): 705-713.

23 Alves AN, Fernandes KP, Melo CA et al. Modulating effect of low level-laser therapy on fibrosis in the repair process of the tibialis anterior muscle in rats. Lasers Med Sci 2014; 29(2): 813-821.

24 Hillmann G, Steinkamp-Zucht A, Geurtsen W et al. Culture of primary human gingival fibroblasts on biodegradable membranes. Biomaterials 2002; 23(6): 1461-1469.

25 Eguchi T, Kubota S, Kawata K et al. Different transcriptional strategies for ccn2/ctgf gene induction between human chondrocytic and breast cancer cell lines. Biochimie 2007; 89(3): 278-288.

26 Black SA Jr., Palamakumbura AH, Stan M et al. Tissue-specific mechanisms for CCN2/ CTGF persistence in fibrotic gingiva: interactions between CAMP and MAPK signaling pathways, and prostaglandin E2-EP3 receptor mediated activation of the C-JUN N-terminal kinase. J Biol Chem 2007; 282(21): 15416-15429.

27 Schiller M, Dennler S, Anderegg U et al. Increased cAMP levels modulate transforming growth factor-beta(TGF- $\beta$ )/Smad-induced expression of extracellular matrix components and other key fibroblast effector functions. J Biol Chem 2010; 285(1): 409-421.

28 Swaney JS, Roth DM, Olson ER et al. Inhibition of cardiac myofibroblast formation and collagen synthesis by activation and overexpression of adenylyl cyclase. Proc Natl Acad Sci USA 2005; 102(2): 437-442.

29 Huang SK, Wettlaufer SH, Chung J et al. Prostaglandin E2 inhibits specific lung fibroblast functions via selective actions of PKA and Epac-1. Am J Respir Cell Mol Biol 2008; 39(4): 482-489.

$30 \mathrm{Wu}$ JY, Chen $\mathrm{CH}$, Yeh LY et al. Low-power laser irradiation promotes the proliferation and osteogenic differentiation of human periodontal ligament cells via cyclic adenosine monophosphate. Int J Oral Sci 5(2): 85-91.

(c) (i) (2) This work is licensed under a Creative Commons Attributioncc. No NA SA Nommercial-ShareAlike 4.0 International License. The images or other third party material in this article are included in the article's Creative Commons license, unless indicated otherwise in the credit line; if the material is not included under the Creative Commons license, users will need to obtain permission from the license holder to reproduce the material. To view a copy of this license, visit http:// creativecommons.org/licenses/by-nc-sa/4.0/

(C) The Author(s) 2017

Supplementary Information for this article can be found on the International Journal of Oral Science website (http://www.nature.com/ijos) 